\title{
Uterus-preserving Laparoscopic Lateral Suspension with Mesh Operation in Pelvic Organ Prolapse: Initial Experience in a Single Tertiary Center with a Median 24-Month Follow-up
}

\author{
Uteruserhaltende laparoskopisch-laterale Suspension \\ mit Netzimplantat zur Behandlung des urogenitalen Deszensus: \\ erste Erfahrungen in einem Krankenhaus der Maximalversorgung \\ bei einer mittleren Follow-up-Dauer von 24 Monaten
}

\section{(c) 98}

Authors

Murat Yassa, Niyazi Tug

Affiliation

Department of Obstetrics and Gynecology, Health Sciences University, Sancaktepe Sehit Prof. Dr. Ilhan Varank Training and Research Hospital, Istanbul, Turkey

Key words

abdominocervicopexy, laparoscopic lateral mesh suspension, pelvic organ prolapse, transperineal ultrasonography, uterus preservation

Schlüsselwörter

abdominelle Zervikopexie, laparoskopisch-laterale

Suspension mit Netzimplantat, urogenitaler Deszensus, transperinealer Ultraschall, Erhalt der Gebärmutter

received 31.3.2019

revised 25.5.2019

accepted 27.5.2019

Bibliography

DOI https://doi.org/10.1055/a-0941-3485

Published online 5. 8. 2019 | Geburtsh Frauenheilk 2019; 79 983-992 @ Georg Thieme Verlag KG Stuttgart · New York । ISSN 0016-5751

Correspondence

Dr. Murat Yassa

Health Sciences University, Sancaktepe Sehit Prof. Dr. Ilhan Varank Training and Research Hospital, Department of Obstetrics and Gynecology

Dr. Suphi Ezgi street, No: 10/9, Istanbul, 34704, Turkey

murat.yassa@gmail.com

\section{ABSTRACT}

Introduction Laparoscopic lateral suspension with mesh (LLSM) is an effective and less invasive technique for the correction of pelvic organ prolapse. We discuss the primary objectives, subjective success rate and pelvic floor ultrasound outcomes of uterus-preserving LLSM operations.

Patients and Methods Seventeen patients who underwent uterus-preserving LLSM (abdominocervicopexy) in a tertiary center were included in this prospective study. Anatomical cure was defined separately for the apical and anterior compartments as a Pelvic Organ Prolapse Quantification (POP-Q) score of less than $-1 \mathrm{~cm}$ for each compartment. Subjective cure was defined as the absence of bulge symptoms. Patient satisfaction, sexual function, prolapse-related quality of life, voiding dysfunction, nocturia and constipation were assessed. Transperineal ultrasonography was used to measure anterior compartment mobility and hiatal anteroposterior diameter.

Results The anatomical cure rate was $100 \%$ for the apical and $88.2 \%$ for the anterior compartment, with one symptomatic stage-II cystorectocele and one asymptomatic stage-II cystocele. The subjective cure and patient satisfaction scores were 94.12 and $100 \%$, respectively. Ba and C points were significantly improved, and vaginal lengthening was $10.14 \pm$ $4.19 \mathrm{~mm}$. Bp ascent was $5.72 \pm 11.27 \mathrm{~mm}(p=0.053)$. Proximal urethral rotation and retrovesical angles were reduced by $6.24 \pm 11.95^{\circ}$ and $27 \pm 47.2^{\circ}$, respectively ( $p 1=0.047$; p2 $=0.032$ ). The hiatal anteroposterior diameter was shortened by $4.36 \%(p=0.039)$. A significant improvement was seen with regard to nocturia episodes but not for constipation. No mesh exposure was observed.

Conclusions Uterus-preserving LLSM (abdominocervicopexy) was found to be effective for the correction of apical and anterior prolapse with high levels of patient satisfaction. Significant improvements in urge symptoms and frequency of nocturia were observed. Pelvic floor ultrasound outcomes 
may be useful when comparing this procedure with other surgical techniques.

\section{ZUSAMMENFASSUNG}

Einleitung Die laparoskopisch-laterale Suspension mit Netzimplantat (LLSM) ist eine effektive und weniger invasive Technik zur Behandlung des urogenitalen Deszensus. Die primären Ziele, subjektive Erfolgsquote und Ultraschallergebnisse der Beckenbodenuntersuchungen nach einem gebärmuttererhaltenden LLSM-Eingriff werden hier vorgestellt.

Patientinnen und Methoden Siebzehn Patientinnen, die sich einem gebärmuttererhaltenden LLSM-Eingriff (abdominale Zervikopexie) in einem Krankenhaus der Maximalversorgung unterzogen, wurden in diese prospektive Studie aufgenommen. Die anatomische Heilungsrate wurde als ein Pelvic Organ Prolapse Quantification-(POP-Q-)Wert von weniger als $-1 \mathrm{~cm}$ für das apikale und für das anteriore Kompartiment definiert. Die subjektive Heilung wurde als das Fehlen von Ausbuchtungssymptomen definiert. Patientenzufriedenheit, Sexualfunktion, deszensusassoziierte Lebensqualität, Blasenentleerungsstörungen, Nykturie und Obstipation wurden evaluiert. Die Mobilität des anterioren Kompartiments und der anteroposteriore Durchmesser des Hiatus wurden mithilfe des transperinealen Ultraschalls gemessen.
Ergebnisse Die anatomische Heilungsrate betrug 100\% für das apikale und 88,2\% für das anteriore Kompartiment. Eine Patientin hatte nach dem Eingriff eine symptomatische Zystorektozele 2 . Grades, und eine Patientin hatte eine asymptomatische Zystozele 2. Grades. Die subjektive Heilungsrate und der Patientenzufriedenheitswert betrug jeweils 94,12 bzw. 100\%. Es gab eine signifikante Verbesserung bei den Orientierungspunkten Ba und $C$, und die vaginale Verlängerung betrug 10,14 $\pm 4,19 \mathrm{~mm}$. Der Orientierungspunkt Bp stieg um 5,72 $\pm 11,27 \mathrm{~mm}(p=0,053)$. Die urethrale Rotation and die retrovesikalen Winkel verkleinerten sich um jeweils $6.24 \pm 11.95^{\circ}$ bzw. $27 \pm 47.2^{\circ}$ (p1 =0,047; p2 =0,032). Der anteroposteriore Durchmesser des Hiatus verkürzte sich um $4,36 \%(p=0,039)$. Es gab eine signifikante Verbesserung hinsichtlicher der Nykturieepisoden, nicht aber bei der Obstipation. Es gab keinen Fall von Netzerosion.

Schlussfolgerungen Die gebärmuttererhaltende LLSM (abdominale Zervikopexie) erwies sich als effektive Methode für die Korrektur des apikalen und anterioren Deszensus mit hohen Patientenzufriedenheitswerten. Es gab auch signifikante Verbesserungen bei den Symptomen der Dranginkontinenz und der Häufigkeit der Nykturie. Die Ultraschallergebnisse der Beckenbodenmessungen könnten sich als nützlich erwiesen, um dieses Behandlungskonzept mit anderen chirurgischen Eingriffen zu vergleichen.

\section{Introduction}

Pelvic organ prolapse (POP) is a major health problem which affects the psychological well-being of women [1]. The lifetime risk for POP surgery is reported to be $12.6 \%$ and the annual risk is 4.3 per 1000 women [2]. Apical prolapse constitutes one of the most important issues in pelvic organ prolapse.

It is known that apical prolapse has a strong association with anterior vaginal wall defects. Anterior prolapse repairs should usually be accompanied by apical support, particularly in cases with transverse detachment of the endopelvic fascia from the cervical apex [3]. Laparoscopic lateral suspension with mesh (LLSM) is a promising new technique originally introduced by Dubuisson et al. [4] for the treatment of apical defects and additionally improves anterior defects. Dubuisson et al. were inspired by the method described by Kapandji [5]. The method consisted of laparascopic fixation of the lateral vaginal fornices to the lateral abdominal wall through subperitoneal tunnels parallel to the ovarian vessels using a T-shaped polypropylene mesh. This not only suspends the prolapsed pelvic organs but also reinforces the pubocervical fascia at the apex, thereby improving bladder symptoms. The technique has since been improved and now has the potential to function as an alternative to sacrocolpopexy, a globally accepted method for apical prolapse surgery $[6,7]$. It has been suggested that avoiding the potential risks associated with promontory dissection is one of the most important features of lateral suspension. Uterus preservation is the current trend in gynecologic surgery and hence in POP surgery. Uterus preservation should be offered to appropriate candidates as the primary option to de- crease surgical morbidity and the morbidities associated with reoperation for mesh erosion without worsening the risk of prolapse recurrence [8].

An effective method for the evaluation of pelvic floor anatomy, pelvic floor ultrasonography is increasingly used for the evaluation of women with pelvic floor dysfunction. The transperineal approach allows the functional anatomy of the pelvic floor to be assessed and is also an effective method for the evaluation of objective surgical success [9].

Lateral suspension was introduced as an alternative to sacropexy; however, the majority of the available data in the literature was produced by a single group [6,7,10-13]. External prospective studies are needed to confirm their outcomes. In this prospective study, we aimed to share our preliminary results for uterus-preserving laparoscopic lateral mesh suspension (abdominocervicopexy) operations evaluated by transperineal ultrasonography and subjective assessments.

\section{Materials and Methods}

This prospective study was approved by the local clinical research ethics board and registered with the National Clinical Trials Registry (NCT \#03387202). This study was conducted in a tertiary training and research hospital between November 2016 and December 2017. We aimed to include 15 patients to establish our initial learning curve and finally included 17 patients who underwent uterus-preserving laparoscopic lateral mesh suspension (abdominocervicopexy). 
Subjects were eligible if they consented to uterus-preserving lateral abdominocervicopexy for symptomatic apical pelvic organ prolapse of stage 2 or higher. Patients who preferred other POP surgical techniques or pessaries were excluded from the study. Hysterectomized patients and patients with a suspected gynecological malignancy or premalignant lesions were also excluded. Patients were approached and enrolled at the time of giving their written consent to surgery. All surgeries were performed by the same surgical team.

\section{Surgical technique}

All operations were performed under general anesthesia. Antibiotic prophylaxis with cefazolin $1 \mathrm{~g}$ administered intravenously as a single shot was given to all women at least 30 minutes prior to surgery. Pneumoperitoneum was achieved with a transumbilical 10-mm trocar. Two ancillary 5-mm suprapubic ports were placed lateral to the inferior epigastric vessels bilaterally. Laparoscopy was used to incise the vesicouterine fold, and the bladder was dissected to expose the vaginal wall.

As described previously [14], a V-shaped 2-cm wide strip was prepared by cutting two edges off a $30 \times 30 \mathrm{~cm}$ polypropylene macropore mesh (Parietene ${ }^{\mathrm{TM}}$, Sofradim-Covidien, Trévoux, France) with scissors. We individualized the corner of the $\mathrm{V}$-mesh by adding a $2 \times 2 \mathrm{~cm}$ diamond-shaped extension to treat accompanying anterior wall defects ( $\triangleright$ Fig. 1). The bottom corner of the diamond-shaped extension of the $\mathrm{V}$-mesh was placed and fixed on the anterior part of the cervix with a delayed absorbable tacker device (Absorba Tack ${ }^{\mathrm{TM}}$ Covidien, Mansfield, MA, USA). The mesh was tacked to the cervix four to six times. The anterior corner of the "V" was laid over the vaginal fascia under the bladder without fixation.

The 3-cm skin incisions were made on either of the abdomen, about $3-4 \mathrm{~cm}$ superior and lateral to the anterior-superior iliac spine. Great care was taken to ensure that the incision sites were at least $2 \mathrm{~cm}$ distant from the iliac crest. The abdominal muscles were then perforated with a laparoscopic grasper and the subperitoneal space was entered while the visceral peritoneum was left intact. Subperitoneal tunnels were created by pushing the grasper caudally just above and parallel to the ovarian vessels. After passing the ovaries, the grasper was directed towards the midline and advanced through the leaflets of the broad ligament to reach the prepared vesicouterine space. The arms of the mesh were grasped and pulled throughout the tunnels symmetrically until the external cervical ostium was suspended just above the level of the ischial spines. The mesh was then fixed to the fascia of the external oblique muscles by suturing on each side with 3.0 propylene (Prolene ${ }^{\circledR}$, Ethicon, Johnson \& Johnson Int., Belgium). The remaining $1 \mathrm{~cm}$ excess of the arms was introduced bluntly under the external oblique fascia and left tension free. A laparoscopic McCall culdoplasty or prophylactic bilateral salpingectomy was performed concomitantly when needed. The main steps of the Dubuisson technique are shown in $\mathbf{~ F i g . ~} 2$ with minor modifications.

\section{Preoperative and postoperative assessment}

Baseline data include demographics, medical history, and physical and sonographic examinations. A simplified Pelvic Organ Prolapse Quantification grading system (POP-Q) was used to assess the de-

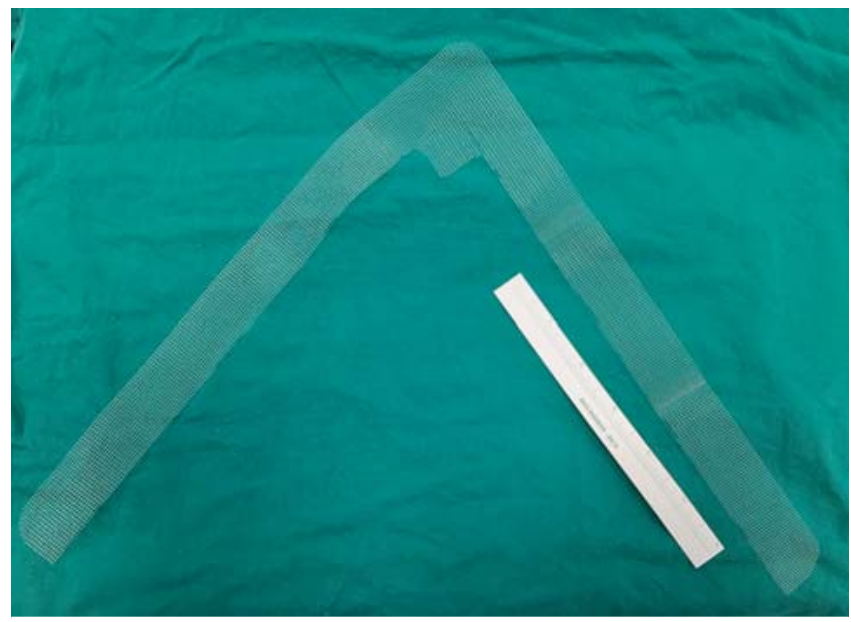

- Fig. 1 V-shaped mesh with diamond-shaped extension.

gree of prolapse [15]. Definitions were consistent with ICS 2016 terminology. Stress urinary incontinence (SUI) was diagnosed by clinical examination which included the cough-stress test in the supine and standing positions with a $300-\mathrm{ml}$ saline-filled bladder and changes over $30^{\circ}$ in the Q-tip test after a maximum Valsalva maneuver and cough. The severity of existing nocturia, dyspareunia and constipation were assessed by the clinician using a nonvalidated Likert type scale (0-3). Nocturia was scored as follows: $0=$ no, 1 = one episode, 2 = two to three episodes, $3=$ four or more episodes.

Validated versions of the Prolapse Quality of Life (P-QOL) questionnaire [16], Pelvic Organ Prolapse Symptom Score (POP-SS) [17], Female Sexual Function Index (FSFI) [18] and Michigan Incontinence Severity Index (M-ISI) [19] were used to assess subjective improvements.

On the second postoperative day the visual analog score (VAS) was used to measure postoperative pain and the Patient Global Impression of Improvement (PGI-I) questionnaire [20] was used at the last postoperative visit to evaluate the patients' postoperative improvement. Complications of surgery were assessed using the Clavien-Dindo classification [21].

Pelvic floor ultrasonography was performed by the first author using 3D convex probes and the Mindray DC-8 PRO ultrasound device (Shenzhen Mindray Bio-medical Electronics Co. Ltd., China) according to the method described by Shek and Dietz [9]. Patients were asked to perform a maximum Valsalva maneuver for at least six seconds to avoid levator co-activation. Cystoceles were evaluated using the Green classification [22]. Patients with a retrovesical angle (RVA) of more than or below $140^{\circ}$ were classified as Green Type II and III, respectively. RVA was defined as the angle between the proximal urethra and the trigonal surface of the bladder. The inferior margin of the pubic symphysis was taken as the line of reference [23]. Cystocele and rectocele descent of at least 10 and $15 \mathrm{~mm}$, respectively, below the pubic symphysis and uterine descent of more than $15 \mathrm{~mm}$ at maximum Valsalva were regarded as significant $[9,23]$. Proximal urethral rotation measurements were obtained at rest and on Valsalva with introital sonography. The hiatal anteroposterior (AP) diameter which indi- 

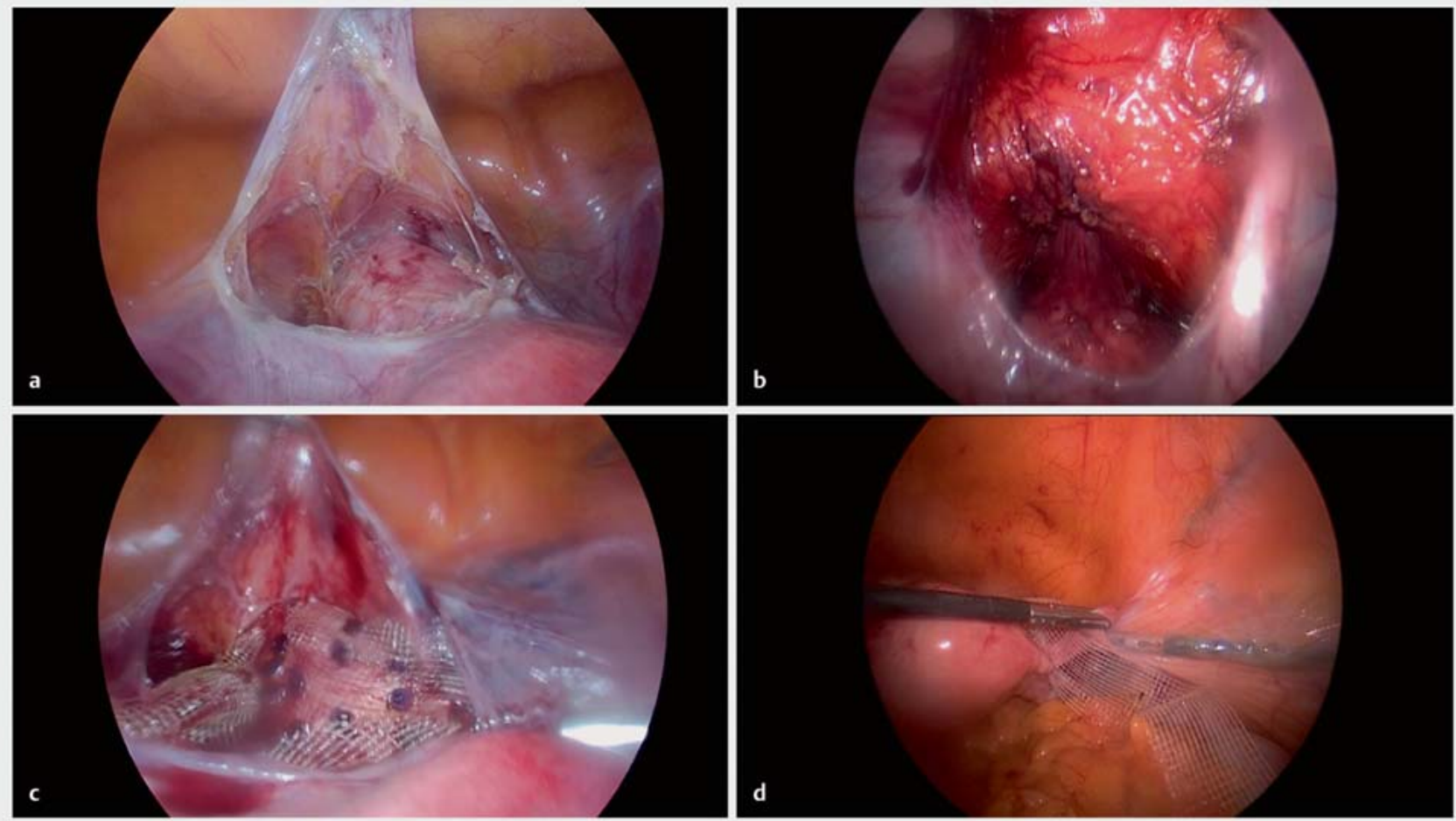

- Fig. 2 Dubuission technique with minor modifications. a Preparation of the cervix and vesicovaginal space; $\mathbf{b}$ Filling of the bladder to make deep dissection of the vesicovaginal space easier when treating the anterior prolapse; c Mesh fixation over the cervix with an absorbable tacker; d A subperitoneal tunnel is formed in the direction of the lower third of the round ligament.

cates hiatal ballooning was measured on maximal Valsalva as the shortest distance from the posteroinferior margin of the pubic symphysis to the anterior margin of the most central aspect of the puborectalis muscle in the midsagittal view. Cervical length and uterus size were also measured in each patient.

\section{Outcome measures}

The primary outcome measures were anatomical and subjective cure, measured at the last follow-up visit. Anatomical cure was defined separately for the apical and the anterior compartment as POP-Q scores for the sites $C$ and Ba of less than $-1 \mathrm{~cm}$, respectively. Subjective cure was defined as the absence of bulge symptoms with the patient answering "Never" to question \#A1 (A feeling of something coming down from or in your vagina?) of the POP-SS scale [17]. Patient satisfaction was assessed using the PGI-I at the last follow-up and considered to be satisfactory when the PGI-I was answered with "much better" or "very much better" [20]. Secondary outcome measures were the scores of the P-QOL, POP-SS, FSFI and M-ISI. Tertiary outcome measures were transperineal pelvic floor ultrasonography results including anterior compartment mobility and the extent of pelvic organ descent (detailed in the results), reoperation rate, mesh-related complications and improvements in constipation, frequency of nocturia, pelvic pain and dyspareunia.

\section{Statistical analysis}

SPSS-22 software was used for data analysis. The KolmogorovSmirnov test was used to assess normality. Normally and non-normally distributed paired groups for preoperative and postoperative outcomes were compared using paired samples t-test and Wilcoxon signed rank test with Monte Carlo simulation, as appropriate. Variables were reported by their mean \pm standard deviation $(\mathrm{SD})$, median, minimum, maximum values. A p-value of less than 0.05 was considered significant.

\section{Results}

Demographic data including age, body mass index, parity, menopausal status and sexual activity are summarized in $>$ Table 1 . Five patients reported themselves as sexually inactive; in four cases this was partner-related. The last follow-up visits to assess the outcome measures were in March 2019. The median follow-up was 23.93 months with a range of 15.3-28.8 months (interquartile range $=3.9$ ).

Mean uterus size was $54.76 \pm 13.33 \mathrm{~mm}$ (height) $\times 39.86 \pm 11.45 \mathrm{~mm}$ (width), and mean cervical length was $30.61 \pm 6.49 \mathrm{~mm}$.

\section{Primary outcomes}

Preoperative Ba, C, Bp and vaginal length (VL) measurements were $17.59 \pm 13.13 \mathrm{~mm}, 36.65 \pm 12.52 \mathrm{~mm},-1.05 \pm 13.41 \mathrm{~mm}$ and $96.62 \pm 12.36 \mathrm{~mm}$, respectively. Anatomical cure was $100 \%$ 
- Table 1 Demographic, pre- and postoperative data.

\begin{tabular}{|c|c|}
\hline Age (year, mean \pm SD) & $52.3 \pm 11.7$ \\
\hline BMI $\left(\mathrm{kg} / \mathrm{m}^{2}\right)$, mean $\pm \mathrm{SD}$ & $29 \pm 3.9$ \\
\hline Parity, mean \pm SD & $3.4 \pm 2.1$ \\
\hline Post-menopausal, n (\%) & $9(53)$ \\
\hline Sexual activity, n (\%) & $12(70.6)$ \\
\hline Previous POP surgery, $\mathrm{n}(\%)$ & $2(11.8)$ \\
\hline - \# 1 & anterior colporrhaphy \\
\hline - \#2 & $\begin{array}{l}\text { sacrouterine ligament } \\
\text { plication, sacrospinous } \\
\text { ligament fixation, } \\
\text { sacrocervicopexy }\end{array}$ \\
\hline \multicolumn{2}{|l|}{ Additional surgical procedures, n (\%) } \\
\hline - prophylactic bilateral salpingectomy & $6(35.3)$ \\
\hline - McCall culdoplasty & $2(11.8)$ \\
\hline - subtotal hysterectomy & $1(5.9)$ \\
\hline - tubal ligation & $1(5.9)$ \\
\hline - extensive adhesiolysis & $2(11.8)$ \\
\hline - myomectomy & $1(5.9)$ \\
\hline - umbilical hernia repair & $1(5.9)$ \\
\hline Operation time (minutes, mean \pm SD) & $108.8 \pm 29.8$ \\
\hline Median VAS score at $48 \mathrm{~h}$ postop (min-max) & $1(1-3)$ \\
\hline \multicolumn{2}{|l|}{ Postop. complications (Clavien-Dindo), n (\%) } \\
\hline - none & $0(0)$ \\
\hline - grade 4 & $1(5.9)$ \\
\hline \multicolumn{2}{|l|}{ Re-operation, n (\%) } \\
\hline - anterior/posterior colporrhaphy & $1(5.9)$ \\
\hline Lower urinary tract infection, n (\%) & $1(5.9)$ \\
\hline De novo stress urinary incontinence, $\mathrm{n}(\%)$ & $0(0)$ \\
\hline De novo overactive bladder, n (\%) & $2(11.8)$ \\
\hline Exacerbation of existing rectocele, n (\%) & $0(0)$ \\
\hline De novo constipation, n (\%) & $1(5.9)$ \\
\hline
\end{tabular}

for the apical compartment and $88.2 \%$ for the anterior compartment, with one symptomatic and one asymptomatic case with stage 2 cystocele ( $\bullet$ Table 2 ). There was no significant improvement in the posterior compartment $(p=0.5)$. Ba and $C$ points were significantly improved, and vaginal lengthening was $10.14 \pm 4.19 \mathrm{~mm}$ ( $\vee$ Table 3 ). The Bp point was not significantly changed by the operation $(p=0.053)$, although an average ascent of $5.72 \pm 11.27 \mathrm{~mm}$ was observed.

Symptomatic recurrence was seen in 1 patient with cystocele and rectocele who was treated with anterior and posterior colporrhaphy one year after the operation. There was no de novo SUI or exacerbation of the existing rectocele. De novo overactive bladder was seen in two patients and resolved with short-term anticholinergic therapy and behavioral changes. De novo constipation was seen in one patient who was diagnosed by general surgeons with inflammatory bowel disease and treated successfully with the appropriate medical therapy. Sterile pyuria was seen in one patient
- Table 2 Objective cure. Pre- and postoperative distribution of prolapse stage according to anatomic compartments.

\begin{tabular}{|c|c|c|c|}
\hline & $\begin{array}{l}\text { Preoperative, } \\
\text { n (\%) }\end{array}$ & $\begin{array}{l}\text { Postopera- } \\
\text { tive, } n(\%)\end{array}$ & $p(z)$ \\
\hline Apical & & & $<0.01(-3.7)^{*}$ \\
\hline - Stage 0 & $0(0)$ & $17(100)$ & \\
\hline - Stage 1 & $0(0)$ & $0(0)$ & \\
\hline - Stage 2 & $2(11.8)$ & $0(0)$ & \\
\hline - Stage 3 & $6(35.3)$ & $0(0)$ & \\
\hline - Stage 4 & $9(52.9)$ & $0(0)$ & \\
\hline Anterior & & & $<0.01(-3.6)^{*}$ \\
\hline - Stage 0 & $1(5.9)$ & $11(64.7)$ & \\
\hline - Stage 1 & $3(17.6)$ & $4(23.5)$ & \\
\hline - Stage 2 & $6(35.3)$ & $2(11.8)$ & \\
\hline - Stage 3 & $5(29.4)$ & $0(0)$ & \\
\hline - Stage 4 & $2(11.8)$ & $0(0)$ & \\
\hline Posterior & & & $0.5(-1)$ \\
\hline - Stage 0 & $11(64.7)$ & $12(70.6)$ & \\
\hline - Stage 1 & $5(29.4)$ & $4(23.5)$ & \\
\hline - Stage 2 & $1(5.9)$ & $1(5.9)$ & \\
\hline Enterocele & & & $0.25(-1.4)$ \\
\hline - Absent & $15(88.2)$ & $17(100)$ & \\
\hline - Present & $2(11.8)$ & $0(0)$ & \\
\hline \multicolumn{4}{|c|}{ Wilcoxon signed rank test with Monte Carlo simulation } \\
\hline
\end{tabular}

in the early postoperative period and successfully treated with antibiotic therapy without any recurrence.

16 out of 17 patients answered "Never" to the "A feeling of something coming down from or in your vagina?" question, indicating the absence of bulge symptoms. All patients reported an improvement in their condition. Improvement after the operation was reported as "very much better" by $88.2 \%$ of the patients and "much better" by the remaining $11.8 \%$. Subjective cure and patient satisfaction rates were 94.12 and $100 \%$, respectively.

\section{Secondary outcomes}

A significant improvement after surgery was seen for all subjective measures and their sub-domains ( $p<0.05$, $\triangleright$ Table 4$)$.

The POP-SS question \#8 (The symptom most frequently reported as causing the most bother) was answered with \#7 (A feeling that your bowel has not emptied completely) by two patients $(11.8 \%)$ while remaining $15(88.2 \%)$ answered the question with "not applicable".

FSFI was only administered to the 12 sexually active patients (70.6\%) as appropriate. Of the five preoperatively sexually inactive patients, four were inactive due to partner-related problems and the remaining one returned to sexual activity postoperatively, but her data were not included in the statistical analysis. 
- Table 3 Pre- and postoperative POP-Q measurements.

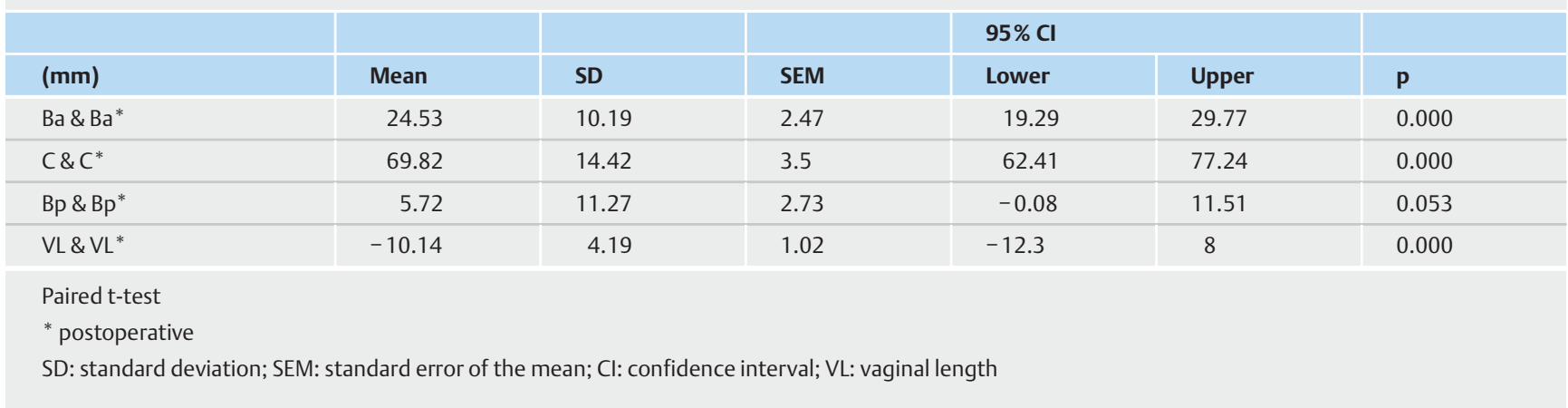

- Table 4 Comparison of pre- and postoperative quality of life scales.

\begin{tabular}{|c|c|c|c|c|c|c|}
\hline & & \multicolumn{2}{|l|}{ Preoperative } & \multicolumn{2}{|c|}{ Postoperative } & \multirow[t]{2}{*}{$\mathrm{p}(\mathrm{z})$} \\
\hline & & Mean \pm SD & Min-Max & Mean \pm SD & Min-Max & \\
\hline \multirow[t]{11}{*}{$\mathrm{P}-\mathrm{QOL}$} & General health perceptions & $2.47 \pm 0.94$ & $1-4$ & $1.18 \pm 0.81$ & $0-2$ & $0.003(-2.84)$ \\
\hline & Prolapse impact & $3.71 \pm 0.59$ & $2-4$ & $1.06 \pm 0.43$ & $0-2$ & $0.000(-3.78)$ \\
\hline & Bladder functions & $31.30 \pm 9.66$ & $14-48$ & $17.65 \pm 5.16$ & $11-30$ & $0.000(-3.50)$ \\
\hline & Bowel functions & $15.89 \pm 5.50$ & $6-25$ & $8.71 \pm 4.95$ & $0-20$ & $0.000(-3.16)$ \\
\hline & Role limitations & $6.65 \pm 2.03$ & $2-8$ & $2.18 \pm 0.53$ & $2-4$ & $0.000(-3.47)$ \\
\hline & Physical limitations & $10.70 \pm 6.70$ & $2-75$ & $2.47 \pm 0.80$ & $2-4$ & $0.000(-3.55)$ \\
\hline & Social limitations & $6.30 \pm 2.08$ & $2-8$ & $2.12 \pm 0.33$ & $2-3$ & $0.000(-3.57)$ \\
\hline & Personal relationships & $9.23 \pm 2.89$ & $3-12$ & $1.76 \pm 1.68$ & $0-5$ & $0.000(-3.64)$ \\
\hline & Emotions & $8.94 \pm 2.33$ & $5-12$ & $3.59 \pm 0.94$ & $3-6$ & $0.000(-3.42)$ \\
\hline & Sleep/Energy & $5.94 \pm 1.78$ & $2-8$ & $2.71 \pm 1.26$ & $2-7$ & $0.000(3.54)$ \\
\hline & Severity measures & $11.82 \pm 3.90$ & $5-16$ & $4.59 \pm 0.87$ & $4-7$ & $0.000(-3.63)$ \\
\hline POP-SS & Total & $20.89 \pm 5.74$ & $9-28$ & $5.06 \pm 4.66$ & $0-17$ & $0.000(-3.62)$ \\
\hline \multirow[t]{7}{*}{ FSFI } & Desire & $2.05 \pm 1.30$ & $1.2-5.4$ & $3.4 \pm 1.39$ & $1.2-6$ & $0.011(-2.46)$ \\
\hline & Arousal & $1.90 \pm 1.27$ & $0-3.9$ & $3.45 \pm 1.85$ & $0-5.7$ & $0.015(-2.41)$ \\
\hline & Lubrication & $2.12 \pm 1.61$ & $0-4.8$ & $4.15 \pm 1.69$ & $0-6$ & $0.001(-2.94)$ \\
\hline & Orgasm & $1.80 \pm 1.60$ & $0-4.4$ & $3.73 \pm 1.74$ & $0-6$ & $0.001(-2.94)$ \\
\hline & Satisfaction & $2.50 \pm 1.62$ & $0-5.2$ & $4.17 \pm 1.27$ & $1.2-5.6$ & $0.024(-2.25)$ \\
\hline & Pain & $2.00 \pm 1.76$ & $0-5.2$ & $5.10 \pm 1.70$ & $0-6$ & $0.001(-2.94)$ \\
\hline & Total & $12.37 \pm 7.36$ & $1.2-26.5$ & $24 \pm 7.98$ & $6.4-34.6$ & $0.001(-2.98)$ \\
\hline \multirow[t]{5}{*}{ M-ISI } & Stress urinary incontinence & $3.18 \pm 3.20$ & $0-10$ & $1.29 \pm 2.31$ & $0-6$ & $0.002(-2.82)$ \\
\hline & Urge urinary incontinence & $6.06 \pm 3.70$ & $0-12$ & $2.00 \pm 2.55$ & $0-9$ & $0.000(-3.53)$ \\
\hline & Pad use & $3.88 \pm 1.80$ & $0-6$ & $1.71 \pm 1.86$ & $0-5$ & $0.002(-3.02)$ \\
\hline & Bother score & $2.53 \pm 2.37$ & $0-7$ & $0.71 \pm 1.26$ & $0-4$ & $0.013(-2.4)$ \\
\hline & Severity score & $13.12 \pm 6.48$ & $1-25$ & $5.00 \pm 5.76$ & $0-20$ & $0.000(-3.52)$ \\
\hline
\end{tabular}

Wilcoxon signed rank test with Monte Carlo simulation

P-QOL: Prolapse Quality of Life; POP-SS: Pelvic Organ Prolapse - Symptom Score; FSFI: Female Sexual Function Index; M-ISI: Michigan Incontinence Severity Index 
- Table 5 Pelvic floor ultrasonography measurements.

\begin{tabular}{|c|c|c|c|}
\hline & Preoperative (mean \pm SD) & Postoperative (mean \pm SD) & p \\
\hline $\mathrm{UR}\left({ }^{\circ}\right)$ & $28.12 \pm 16.57$ & $21.88 \pm 12.53$ & 0.047 \\
\hline $\operatorname{RVA}\left({ }^{\circ}\right)$ & $131.29 \pm 41.38$ & $104.35 \pm 34.15$ & 0.032 \\
\hline $\mathrm{HD}^{\mathrm{v}}(\mathrm{mm})$ & $68.20 \pm 10.92$ & $64.40 \pm 6.80$ & 0.039 \\
\hline $\mathrm{HD}^{\mathrm{r}}(\mathrm{mm})$ & $71.57 \pm 9.12$ & $68.45 \pm 7.71$ & 0.012 \\
\hline B (mm) & $16.41 \pm 13.75$ & $-3.89 \pm 13.71$ & 0.000 \\
\hline $\mathrm{C}(\mathrm{mm})$ & $26.30 \pm 13.50$ & $-28.90 \pm 8.51$ & 0.000 \\
\hline $\mathrm{R}(\mathrm{mm})$ & $1.67 \pm 8.53$ & $3.15 \pm 12.05$ & 0.565 \\
\hline
\end{tabular}

\section{Tertiary outcomes}

No mesh-related complications were seen in any of the patients during the follow-up periods. Mean operation time was $108.8 \pm 29.8$ minutes. Only one patient was classified as ClavienDindo grade IV due to a misunderstanding by the anesthesiology team about the need for intensive care due to a false suspicion of $\mathrm{CO}_{2}$ embolism. That was the only case of conversion to laparotomy. Significant blood loss was not observed in any cases. SUI was present in four patients preoperatively. All were stress test-positive after the operation and were later treated using a mid-urethral sling in a double-step procedure. However, patient-reported scales indicated significant improvements in subjective stress and urge scores ( $\triangleright$ Table 4 ).

A significant improvement was seen in patients' nocturia and dyspareunia scores but not the constipation scores. The nocturia scores of the patients were $2.00 \pm 0.94$ and $0.59 \pm 0.62$ pre- and postoperatively, respectively $(p=0.000)$. Pre- and postoperative dyspareunia scores of the patients were $2.06 \pm 1.30$ and $0.00 \pm 0.00$, respectively $(p=0.000)$. Constipation scores of the patients were $0.59 \pm 0.80$ and $0.35 \pm 0.49$ pre-and postoperatively $(p=0.102)$.

Transperineal and introital pelvic floor ultrasonography measurements are given in $>$ Table 5 . Urethral mobility was reduced by $6.24 \pm 11.95^{\circ}$ postoperatively $(p=0.047)$. All patients were classified according to their retrovesical angle measurements (RVA). $58.8 \%$ of the patients were classified as Green type II (RVA $\geq 140^{\circ}$ ) with an average of $161 \pm 15.06^{\circ}$, and $41.2 \%$ of the patients were classified as Green type III (RVA $<140^{\circ}$ ) with an average of $108.29 \pm 31.11^{\circ}$. RVA on maximum Valsalva was reduced by $27 \pm 47.2^{\circ}$ after the operation $(p=0.032)$.

The most descended points of the bladder and cervix over the pubic symphysis on maximal Valsalva measured by transperineal ultrasound improved significantly after the operation by 20.3 and $55.2 \mathrm{~mm}$ respectively $(\mathrm{p}=0.000)$. The hiatal AP diameter on Valsalva decreased significantly from $68.2 \pm 10.92 \mathrm{~mm}$ to $64.4 \pm 6.8 \mathrm{~mm}$ before and after the operation ( $p=0.039)$. In contrast, the anorectum of the patients was observed to be descended by $1.48 \pm 10.4 \mathrm{~mm}$ on maximum Valsalva but did not reach the level of statistical significance $(p=0.565)$.
Post-hoc statistical power was assessed using G*Power v. 3.1. (Heinrich Heine University, Düsseldorf, Germany). If the postoperative changes in $C$ and Ba points are taken as the primary outcome measures; the power of this analysis $(n=17)$ was found to be $100 \%$ for both outcomes, with effect sizes of 4.84 and 2.41 , respectively, for $C$ and Ba points and an alpha error of 0.05 .

\section{Discussion}

A wide variety of surgical techniques are used to correct POP, and sacrocolpopexy has been widely accepted as the gold standard for apical prolapse surgery [24]. However, there are major disadvantages associated with this procedure, including the risk of major pelvic vessel or ureteral injury and sacral discitis $[25,26]$. We believe that the sacropexy technique places the uterus in a more posterior position than its normal anatomical position, leaving the anterior compartment unsupported against intraabdominal pressure, which may lead to urge symptoms and de novo anterior prolapse. Because of the aforementioned issues, we preferred to use a lateral suspension operation for POP surgery. In this study, uterus-preserving laparoscopic lateral suspension (abdominocervicopexy) with mesh operation was found to be effective to correct simultaneous apical and anterior compartment prolapse (॰ Fig. 3).

In the original Dubuisson technique, a T-shaped mesh is sutured to the lateral vaginal fornices, and the arms of the mesh are suspended from the vaginal apex towards the lateral abdominal wall between the leaflets of the broad ligament and pulled outside the abdomen at a point $3-4 \mathrm{~cm}$ superior and lateral to the anterior superior iliac spines through a subperitoneal tunnel.

This brilliant technique has not only been shown to be safe and effective in many studies but also provides a more normal anatomical correction $[6,7]$. We have previously made some modifications to this technique [14]: firstly, the cervix was used as the anchoring point instead of the vaginal fornices in order to imitate the cardinal ligament and with the hope of decreasing the risk of mesh detachment and erosion. Secondly, we used a delayed absorbable tacker system instead of suturing in order to decrease the operation time. Thirdly, we fixed the arms of the mesh to the external oblique muscle fascia with Prolene stitches to reduce the 


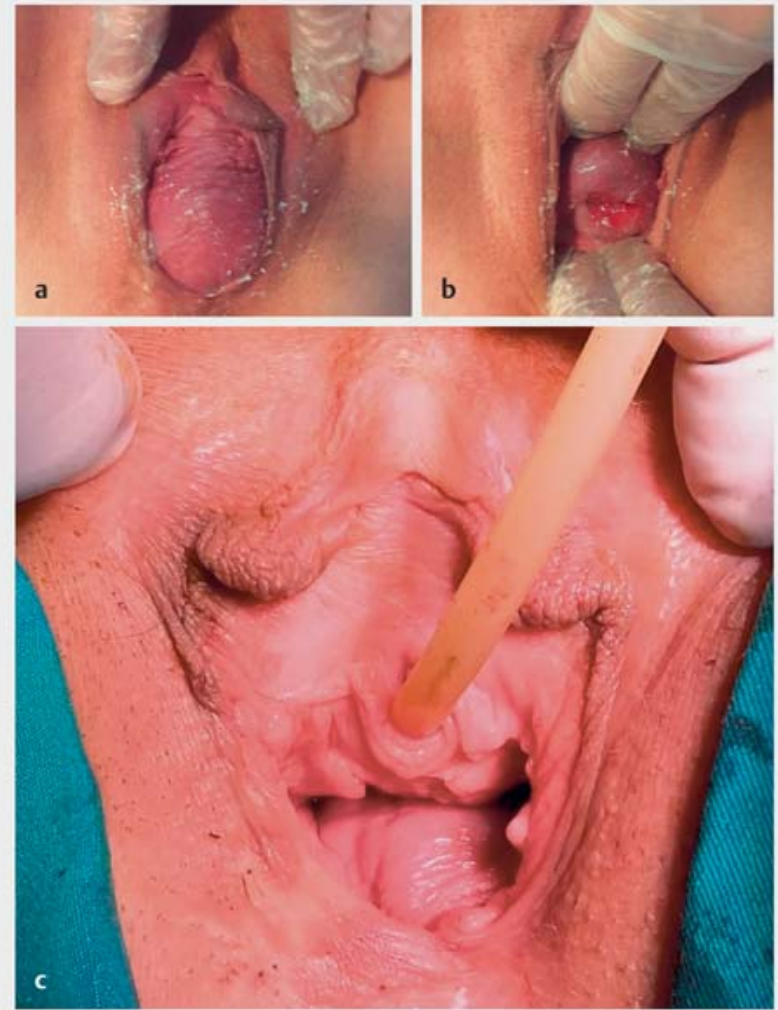

- Fig. 3 a, b Preoperative vaginal examination, c postoperative vaginal examination.

risk of failure. In addition, instead of a T-shaped mesh we used a Vshaped mesh prepared from an ordinary $30 \times 30 \mathrm{~cm}$ macropore polypropylene mesh such as those used by Ceci et al. and also sutured the arms of the mesh to the external oblique muscle fascia [27]. We individualized the shape of the mesh with a diamondshaped extension and prepared a V-shaped mesh for cases with a large additional cystocele and laid the edge of the " $V$ " over the vaginal fascia under bladder without fixation to avoid vaginal mesh erosion.

Recently, the results of the largest series of laparoscopic lateral suspensions with mesh was published by Veit-Rubin et al. A total of 417 patients were operated on. The anatomical success rate was $93.6 \%$ for the apical and $91.6 \%$ for the anterior compartment, and the subjective cure rate was $78.4 \%$ in their first year. They also reported that over $85 \%$ of patients rated their situation as improved and that this satisfaction was associated with the absence of concomitant hysterectomy. Their mesh exposure rate was $4.3 \%$ and the reoperation rate was $7.3 \%$ [7].

In the current study, the uterus was preserved in all 17 of the operated patients. The anatomical success rate for the apical and anterior compartments was 100 and $88.2 \%$, respectively, and the subjective cure and patient satisfaction rates were 94.12 and $100 \%$, respectively. The discrepancy between the subjective cure rate and the patient satisfaction rate could be related to the study size, the preservation of the uterus as suggested by the results of
Veit-Rubin et al. [13] or the slightly different operative technique. We have not seen any patient with mesh exposure and we only reoperated one patient who underwent anterior and posterior colporrhaphy.

Veit-Rubin et al. reported recovered sexual activity for $13.1 \%$ of patients at 1 year after surgery [7]. This was comparable with our results. Mean total FSFI score increased from $12.37 \pm 7.36$ to $24 \pm 7.98$ postoperatively ( $n=12, p<0.05$, $>$ Table 4$)$. In addition, one sexually inactive patient returned to sexual activity after the operation.

Huang et al. reported a higher incidence of voiding dysfunction, weaker pelvic floor support and a more caudally positioned bladder neck in patients with Green type III cystoceles [28]. In those patients, the proximal urethra can be rotated as much as with Green type II cystoceles, resulting in urethral kinking. Urethral mobility was reduced by $22.2 \%\left(6.24 \pm 11.95^{\circ}\right)$ after the operation ( $p=0.047$ ) in the current study. RVA on maximum Valsalva was reduced by $27 \pm 47.2^{\circ}$ postoperatively $(p=0.032)$. Changes in the retrovesical junction might have been largely caused by tissue suspension during fixation and may depend on the type of the cystocele, therefore there may be no direct surgical effect. The change in RVA should be interpreted with caution and cannot be generalized. In this study, it was found that laparoscopic lateral suspension supported the bladder base well and restored the normal anatomy with correction of the retrovesical angle (ฉ Fig. 4).

The integral theory proposed that bladder symptoms originate predominantly from damaged suspensory ligaments and fascia rather than from the bladder itself [29]. Defects in the structures supporting and stretching the vesicovaginal fascia membrane are the cause of several functional urinary symptoms. The loss of support by the trampoline membrane that specifically corresponds to the trigone mainly triggers a premature micturition reflex including nocturia and urge symptoms. Hence it was hypothesized that supporting the anterior and apical compartments would improve those symptoms. The results of the present study were in accordance with the integral theory, with improved voiding dysfunction and urge symptoms as measured by validated questionnaires and a significant decrease in nocturia episodes and dyspareunia. We think that LLSM mimics the cardinal ligament and partially supports the bladder base.

Andrew et al. retrospectively analyzed imaging data from their large and varied POP surgery series to assess changes in the levator hiatus area [30]. POP repair led to minimal but significant shortening in the three-dimensional hiatal area by $9 \%$ measured by transperineal ultrasound. In the current study, the two-dimensional hiatal anteroposterior diameter was found to be shortened by $4.36 \%$, with a mean of $3.12 \pm 4.57 \mathrm{~mm}$, comparable to the results of Andrew et al. Although the rarity of additional posterior compartment surgeries may explain this limited shortening, we believe that shortening of the hiatal AP diameter might be explained by the relief of pressure exerted on the levator muscles following correction of the prolapse and the reinstatement of normal anatomy.

The small study size is the major limitation of the present study. On the other hand, this study was carried out to establish our learning curve for the LLSM operation. This study had three 

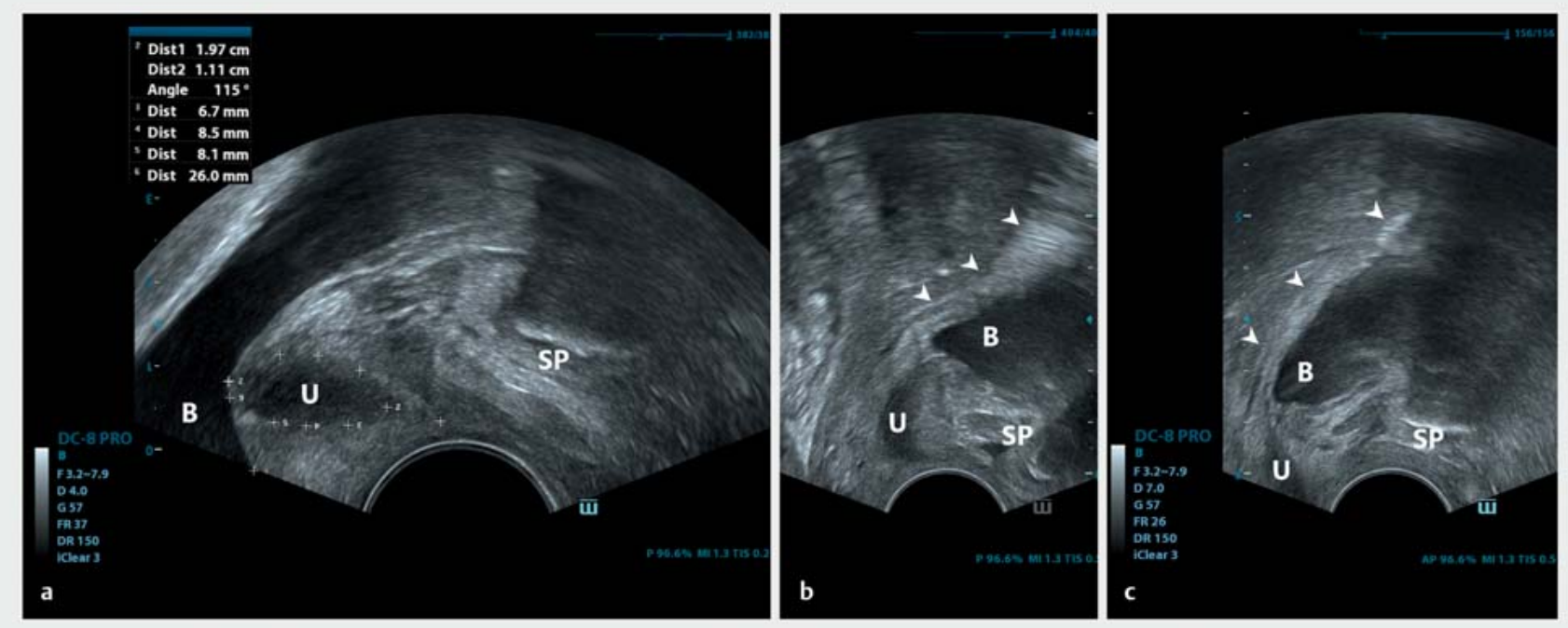

- Fig. 4 Transperineal ultrasonography of the pelvic floor. a Preoperative status: cystourethrocele; b Postoperative correction of anterior prolapse at rest; $c$ Postoperative correction of anterior prolapse on maximal Valsalva. B: bladder; SP: pubic symphysis; U: urethra. Arrows indicate the mesh fixed to the cervix and laid over the anterior vaginal wall. Note the corrected retrovesical angle.

major strengths. Firstly, it was developed as a prospective longitudinal study. Moreover, to the best of our knowledge, this is the first time transperineal ultrasonography was used to evaluate the results of a lateral suspension operation. Finally, unlike most of previous studies, urge symptoms (as measured by POP-QOL and $\mathrm{M}-\mathrm{ISI}$ ) and frequency of nocturia were also assessed as outcomes after prolapse surgery. Significant improvements in both were demonstrated.

\section{Conclusion}

Uterus-preserving laparoscopic lateral suspension (abdominocervicopexy) with mesh operation was found to be safe and effective with high patient satisfaction rates and simultaneous correction of apical and anterior prolapse. Significant improvements in patients' quality of life, frequency of nocturia, urge symptoms and extent of dyspareunia were observed. Pelvic floor ultrasound outcomes may be useful when comparing this approach with other surgical techniques.

\section{Clinical Trials Registry}

NCT \#03387202

\section{Conflict of Interest}

The authors declare that they have no conflict of interest.

\section{References}

[1] Ghetti C, Skoczylas LC, Oliphant SS et al. The emotional burden of pelvic organ prolapse in women seeking treatment: a qualitative study. Female Pelvic Med Reconstr Surg 2015; 21: 332

[2] Wu JM, Matthews CA, Conover MM et al. Lifetime risk of stress incontinence or pelvic organ prolapse surgery. Obstet Gynecol 2014; 123: 1201

[3] Rooney K, Kenton K, Mueller ER et al. Advanced anterior vaginal wall prolapse is highly correlated with apical prolapse. Am J Obstet Gynecol 2006; 195: 1837-1840

[4] Dubuisson J, Chapron C. Laparoscopic iliac colpo-uterine suspension for the treatment of genital prolapse using two meshes: A new operative laparoscopic approach. J Gynecol Surg 1998; 14: 153-159

[5] Kapandji M. [Treatment of urogenital prolapse by colpo-isthmo-cystopexy with transverse strip and crossed, multiple layer, ligamento-peritoneal douglasorrhaphy]. Ann Chir 1967; 21: 321-328

[6] Veit-Rubin N, Dubuisson J-B, Lange $S$ et al. Uterus-preserving laparoscopic lateral suspension with mesh for pelvic organ prolapse: a patient-centred outcome report and video of a continuous series of 245 patients. Int Urogynecol J 2016; 27: 491-493

[7] Veit-Rubin N, Dubuisson J-B, Gayet-Ageron A et al. Patient satisfaction after laparoscopic lateral suspension with mesh for pelvic organ prolapse: outcome report of a continuous series of 417 patients. Int Urogynecol J 2017; 28: 1685-1693

[8] Meriwether KV, Antosh DD, Olivera CK et al. Uterine preservation vs. hysterectomy in pelvic organ prolapse surgery: a systematic review with meta-analysis and clinical practice guidelines. Am J Obstet Gynecol 2018; 219: 129-146.e2

[9] Shek K, Dietz HP. Assessment of pelvic organ prolapse: a review. Ultrasound Obstet Gynecol 2016; 48: 681-692

[10] Dubuisson JB, Chapron C, Fauconnier A et al. Laparoscopic management of genital prolapse: lateral suspension with two meshes. Gynaecological Endoscopy 2000; 9: 363-368 
[11] Dubuisson J, Eperon I, Dällenbach P et al. Laparoscopic repair of vaginal vault prolapse by lateral suspension with mesh. Arch Gynecol Obstet 2013; 287: 307-312

[12] Dubuisson J-B, Yaron M, Wenger J-M et al. Treatment of genital prolapse by laparoscopic lateral suspension using mesh: a series of $73 \mathrm{pa}-$ tients. J Minim Invasive Gynecol 2008; 15: 49-55

[13] Veit-Rubin N, Dubuisson J, Constantin F et al. Uterus preservation is superior to hysterectomy when performing laparoscopic lateral suspension with mesh. Int Urogynecol ] 2019; 30: 557-564

[14] Yassa M, Tug N. Uterus-preserving lateral mesh suspension with minor modification. Eur J Obstet Gynecol Reprod Biol 2019; 234: e236

[15] Swift S, Morris S, McKinnie V et al. Validation of a simplified technique for using the POPQ pelvic organ prolapse classification system. Int Urogynecol ] 2006; 17: 615-620

[16] Cam C, Sakalli M, Ay P et al. Validation of the prolapse quality of life questionnaire (P-QOL) in a Turkish population. Eur J Obstet Gynecol Reprod Biol 2007; 135: 132-135

[17] Özengin N, Kaya S, Orhan C et al. Turkish adaptation of the Pelvic Organ Prolapse Symptom Score and its validity and reliability. Int Urogynecol ] 2017; 28: 1217-1222

[18] Verit FF, Verit A. Validation of the female sexual function index in women with chronic pelvic pain. J Sex Med 2007; 4: 1635-1641

[19] Sargın MA, Yassa M, Taymur BD et al. Adaptation and validation of the Michigan incontinence severity index in a Turkish population. Patient Prefer Adherence 2016; 10: 929

[20] Srikrishna S, Robinson D, Cardozo L. Validation of the Patient Global Impression of Improvement (PGI-I) for urogenital prolapse. Int Urogynecol ] 2010; $21: 523-528$
[21] Dindo D, Demartines N, Clavien PA. Classification of surgical complications: a new proposal with evaluation in a cohort of 6336 patients and results of a survey. Ann Surg 2004; 240: 205-213

[22] Chantarasorn V, Dietz H. Diagnosis of cystocele type by clinical examination and pelvic floor ultrasound. Ultrasound Obstet Gynecol 2012; 39: 710-714

[23] Dietz H, Lekskulchai O. Ultrasound assessment of pelvic organ prolapse: the relationship between prolapse severity and symptoms. Ultrasound Obstet Gynecol 2007; 29: 688-691

[24] Ganatra AM, Rozet F, Sanchez-Salas R et al. The current status of laparoscopic sacrocolpopexy: a review. Eur Urol 2009; 55: 1089-1105

[25] Good MM, Abele TA, Balgobin S et al. Preventing L5-S1 discitis associated with sacrocolpopexy. Obstet Gynecol 2013; 121: 285-290

[26] Akladios CY, Dautun D, Saussine C et al. Laparoscopic sacrocolpopexy for female genital organ prolapse: establishment of a learning curve. Eur J Obstet Gynecol Reprod Biol 2010; 149: 218-221

[27] Ceci F, Spaziani E, Corelli S et al. Technique and outcomes about a new laparoscopic procedure: the Pelvic Organ Prolapse Suspension (POPS). G Chir 2013; 34: 141-144

[28] Huang WC, Yang SH, Yang JM. Clinical importance and surgical outcomes of green type III cystocele in women with anterior vaginal prolapse. J Ultrasound Med 2015; 34: 2279-2285

[29] Liedl B, Inoue H, Sekiguchi Y et al. Update of the integral theory and system for management of pelvic floor dysfunction in females. European Urology Supplements 2017. doi:10.1016/j.eursup.2017.01.001

[30] Andrew BP, Shek KL, Chantarasorn V et al. Enlargement of the levator hiatus in female pelvic organ prolapse: cause or effect? Aust N Z J Obstet Gynaecol 2013; 53: 74-78 